UDC 1:005.35(470.45)

LBC 87.703.3

\title{
SUBJECTS AND ADDRESSEES OF SOCIAL RESPONSIBILITY (ON THE EXAMPLE OF ORGANIZATIONS OF VOLGOGRAD) ${ }^{1}$
}

\author{
Tatyana S. Gorina \\ Volgograd State University, Volgograd, Russian Federation
}

\begin{abstract}
The study is based on the analysis of semi-structured interviews of 15 heads of commercial and non-profit organizations in Volgograd. To process the data obtained during the interview, the method of network thematic analysis was used. The study showed that the socially responsible activities of commercial organizations and NGOs of Volgograd is often defined by relationships between people rather than by relations between companies, which is one of the reasons that encourages actors to personal participation in socially responsible activities and helps to strengthen the positive impact of corporate social responsibility on the society. The moral aspect of these relationships (friendship, trust, care, support, etc.) as the most important component of social capital contributes to the development of socially responsible behavior. The involvement of subjects in socially responsible activities is also influenced by the current social and economic situation in Volgograd. Respondents assign a regulatory role to the state as a subject of social responsibility; they believe that it can act as an initiator of social projects, as well as contribute to the expansion of corporate social responsibility, creating conditions for business development. Representatives of Volgograd organizations help those whose problems, difficulties are clear, cause sympathy due to the personal experience of the subject, personal observations. An important criterion for choosing the recipients of social responsibility is the place of residence of its subjects (help their city, district, take care of the well-being of the local community in the territory of the company's presence). The social responsibility of organizations in Volgograd is determined by goals and motives that go beyond economic expediency (gratitude, pride, duty, loyalty, justice, love for people, etc.). At the same time, the scale of assistance depends, according to respondents, on the availability of free financial resources, which can no longer be spent on business development, employee compensation, personal needs.
\end{abstract}

Key words: socially responsible activity, corporate social responsibility, subjects of social responsibility, addressees of social responsibility, social capital.

УДК 1:005.35(470.45)

ББК 87.703 .3

\section{СУБЪЕКТЫ И АДРЕСАТЫ СОЦИАЛЬНОЙ ОТВЕТСТВЕННОСТИ (НА ПРИМЕРЕ ОРГАНИЗАЦИЙ Г. ВОЛГОГРАДА ${ }^{1}$}

\author{
Татьяна Сергеевна Горина \\ Волгоградский государственный университет, г. Волгоград, Российская Федерация
}

\begin{abstract}
Аннотация. Исследование основано на анализе полуструктурированных интервью 15 руководителей коммерческих и некоммерческих организаций г. Волгограда. Для обработки данных, полученных в ходе интервью, был использован метод сетевого тематического анализа. Исследование показало, что социально ответственная деятельность коммерческих организаций и НКО г. Волгограда часто определяется отношениями, сложившимися между людьми, а не связями между компаниями, что является одной из причин, побуждающих субъектов к личному участию в социально ответственной деятельности, и позволяет усилить позиj. тивное воздействие, которое корпоративная социальная ответственность оказывает на общество. Моральнонравственный аспект этих отношений (дружба, доверие, забота, поддержка и т. д.) в качестве важнейшей составляющей социального капитала способствует развитию социально ответственного поведения. На вово을 леченность субъектов в социально ответственную деятельность влияет и текущая социально-экономическая (0) ситуация в г. Волгограде. Государству в качестве субъекта социальной ответственности респонденты отводят
\end{abstract}




\section{ОСНОВАНИЯ СОЦИАЛЬНОЙ ОТВЕТСТВЕННОСТИ}

регулирующую роль; считают, что оно может выступать в качестве инициатора социальных проектов, а также способствовать распространению корпоративной социальной ответственности, создавая условия для развития бизнеса. Представители организаций г. Волгограда помогают тем, чьи проблемы, трудности понятны, вызывают сочувствие в силу личного опыта субъекта, личных наблюдений. Важным критерием для выбора адресатов социальной ответственности является место проживания ее субъектов (помогают своему городу, району, заботятся о благополучии местного сообщества на территории присутствия компании). Социальная ответственность организаций г. Волгограда обусловлена целями и мотивами, которые выходят за рамки экономической целесообразности (благодарность, гордость, долг, верность, справедливость, любовь к людям и т. п.). При этом масштаб оказываемой помощи зависит, по мнению респондентов, от наличия свободных финансовых средств, которые уже можно не расходовать на развитие бизнеса, оплату труда сотрудников, личные нужды.

Ключевые слова: социально ответственная деятельность, корпоративная социальная ответственность, субъекты социальной ответственности, адресаты социальной ответственности, социальный капитал.

Увеличение ожиданий относительно участия бизнеса в жизни общества, растущая озабоченность общества проблемами нечестного поведения в бизнесе, рост спроса граждан на социальные услуги и отсутствие у государства ресурсов для того, чтобы полностью удовлетворить такой спрос, требует от компаний чувствительности к социально значимым проблемам и навыков для их решения. Среди субъектов социальной ответственности нет единства относительно того, какие проблемы общества являются наиболее значимыми и представители какого сектора - государственного, коммерческого или некоммерческого - должны их решать.

Для изучения указанных тем были использованы качественные методы (полуструктурированное интервью, метод сетевого тематического анализа). Экспертами выступили 15 руководителей коммерческих и некоммерческих организаций г. Волгограда. Каждое из интервью длилось от 30 до 60 минут. Руководителей просили ответить на ряд вопросов, в том числе о том, какие социальные программы, помимо предусмотренных законом, реализуют возглавляемые ими организации. Вопросы также были связаны с тем, получает ли компания преимущества от корпоративной социальной ответственности. Экспертам было предложено уделить особое внимание мотивам участия в социальных проектах; их просили определить, какую роль в развитии корпоративной социальной ответственности играют институты, представляющие различные секторы. Результаты интервью, сгруппированные и сопоставленные, стали основой для данного исследования. Для обработки данных, полученных в ходе интервью, был использован метод сетевого тематического анализа (СТА).

Круг участников социально ответственной деятельности в г. Волгограде (см. рисунок) обусловлен, как показало исследование, небольшими размерами города, что обеспечивает тесные связи между людьми, особенно работающими в одной сфере, отрасли. Последнее нередко предполагает и обучение в одном учебном заведении, на одном или схожем направлении подготовки. Также на то, становится ли компания субъектом социально ответственной деятельности, влияет текущая социально-экономическая ситуация в г. Волгограде: бизнес находится в условиях выживания, а потому регулярные и системные социальные проекты являются для него непосильным бременем.

Указанные факторы часто приводят не к корпоративному, а личному участию субъектов в социально ответственной деятельности: они тратят личные средства, а не ресурсы компании; помогают как жители города, а не как представители организации, а потому не всегда сообщают общественности об оказанной помощи: «То есть мы делаем не за счет средств, которые мы можем списать на это, а просто из своего собственного кармана» (респондент № 12), «Мы не в компании участвуем. Мы лично от своего имени участвуем в этом начинании» (респондент № 14).

Однако публичность социально ответственной деятельности благодаря формированию социального капитала позволяет получить важные для компании преимущества (например, упрощает взаимодействие с контрагентами, принятие решений в пользу компании). Она также способствует масштабиро- 
ванию социально значимых практик. Такого мнения придерживаются не только руководители компаний г. Волгограда, но и другие субъекты социально ответственной деятельности: «Раньше я была убеждена, что благотворительность можно не афишировать, достаточно просто совершать добрые поступки, но сейчас пересмотрела свои взгляды. Благодаря публичности и общественному резонансу наше участие в акции \#ПЛЫВИВОБЛАГО стало примером, положило начало новым акциям. <..> Считаю, что для бизнесменов открытое участие в подобных проектах важно и полезно!» [Ильченко web]. Корпоративная социальная ответственность, о которой известно обществу, может повысить доверие к организациям, что, в свою очередь, может способствовать ослаблению контроля над ними со стороны социальных, в том числе политических, институтов. По мнению Д. Димаейра, «социально ответственные стратегии могут играть критическую роль, поскольку способны улучшать репутацию отрасли в глазах общественности и таким образом делать внешнее вмешательство менее веро- ятным. И наоборот, любой удар по репутации отрасли зачастую приводит к немедленному принятию политических и регулятивных мер» [Маак, Плесс 2008, 214].

Согласно результатам исследования социально ответственная деятельность коммерческих организаций и НКО г. Волгограда часто определяется личными отношениями между людьми, а не взаимодействиями между компаниями. Морально-нравственный аспект этих отношений (дружба, доверие, забота, поддержка и т. д.) - важнейшая составляющая социального капитала, способствующая развитию социально ответственного поведения и определяющая готовность откликнуться на просьбу друзей, знакомых присоединиться к какому-либо социально значимому проекту. Волгоградские предприниматели участвуют во многих проектах потому, что их организуют конкретные люди, с которыми выстроены открытые и доверительные отношения и которых хочется поддержать. Субъекты при этом выступают как носители ролей, не связанных с компанией (отца, матери, друга, однокурсника и т. п.),

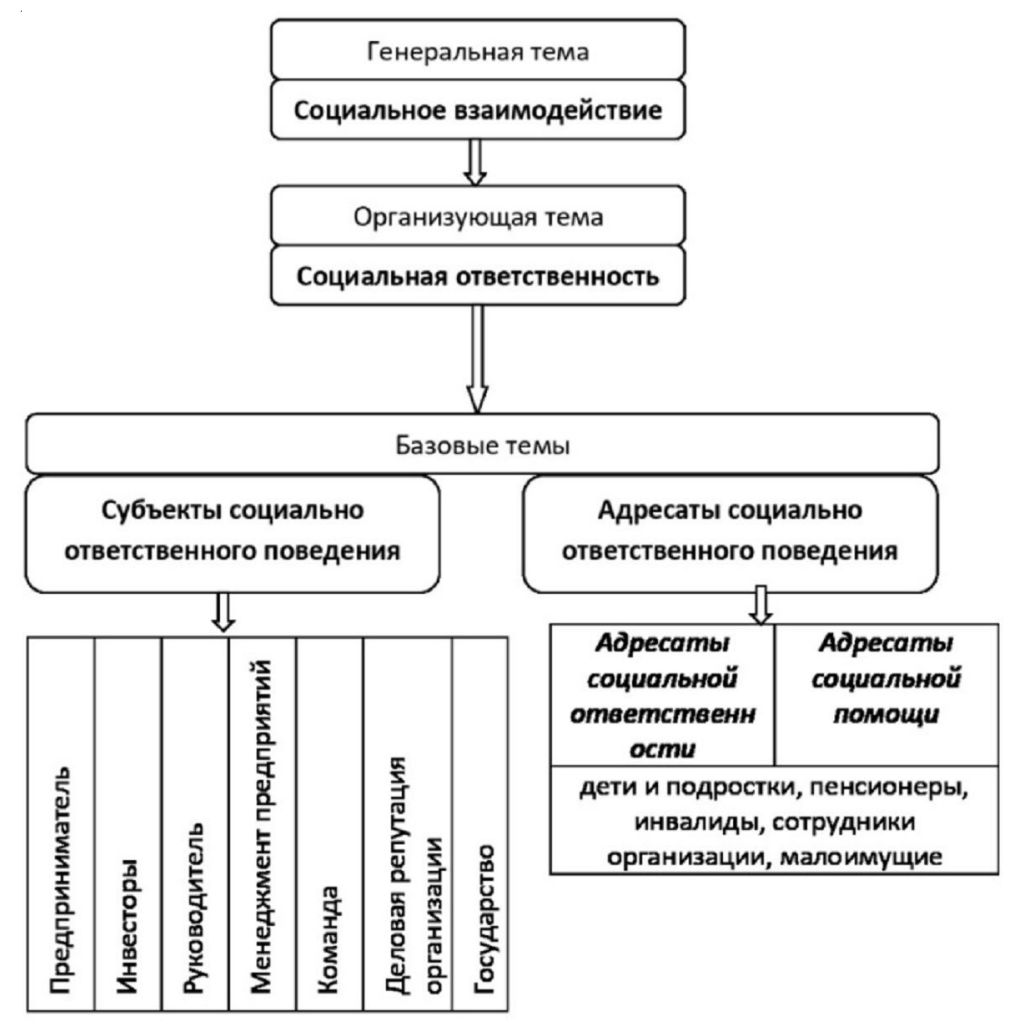

Результаты сетевого тематического анализа по базовым темам

«Субъекты социально ответственного поведения» и «Адресаты социально ответственного поведения» 
предпочитая мобилизовать ресурс этих ролей для организации и реализации социальных проектов. В этих случаях морально-этические основания социального капитала фундируют гораздо более широкие социальные связи за пределами корпоративной социальной ответственности и стимулируют социально ответственное поведение, которое без них было бы невозможно.

Отдельным субъектом социальной ответственности выступает государство, которому многие респонденты отводят регулирующую роль, а также считают или хотели бы видеть его инициатором социальных проектов (в том числе и для того, чтобы информировать бизнес о значимых проблемах, чтобы он мог оказывать государству помощь, выбирая из предложенных властью программ): «Государство в этом случае, наверное, больше инструмент-анализатор, который должен показывать слабые места, куда «руки не доходят», и, наверное, в форме диалога предлагать бизнесу, предлагать обществу рассмотреть те или иные направления, которые сейчас не востребованы» (респондент № 3), «...государство должно дать какие-то программы, чтобы бизнес мог помогать, чтобы не все висело на государстве» (респондент № 6), «Если бы государство каким-то образом стимулировало социальные программы для того, чтобы больше брали молодежь, то я к этому отнесусь хорошо» (респондент № 10). Однако власть на разном уровне способна и сдерживать развитие социально ответственной деятельности. По мнению руководителей компаний, отсутствие со стороны государства стимулов для развития бизнеса препятствует распространению корпоративной социальной ответственности как одного из направлений деятельности коммерческих организаций, потому что лишает их дополнительных средств, необходимых для решения социально значимых задач. Ожидаемая бизнесом заинтересованность государства в развитии социальной ответственности может проявляться в использовании экономических методов стимулирования корпоративной социальной ответственности: снижении налогов, предоставлении льгот при аренде земли, помещений.

Помощь бизнесу в развитии корпоративной социальной ответственности может вы- ражаться и в том, что такая ответственность не перекладывается исключительно на коммерческие организации: социально ответственными должны быть представители всех секторов, все члены общества. Примечательно в этом случае обоснование социально ответственного поведения, социального взаимодействия в целом - любовь к людям, о чем заявляют и другие субъекты социально ответственной деятельности [Велехов web; Моя первая поездка... web; Что движет благотворителями... web].

Помогают тем, чьи проблемы, трудности понятны, вызывают сочувствие в силу личного опыта субъекта, личных наблюдений (есть дети, родственники-пенсионеры; отдыхают в местах, которые завалены мусором; видят разрушенные ступеньки около своего офиса; работают с людьми, попавшими в сложные жизненные ситуации и т. п.). Адресатами социальной ответственности являются как конкретные люди (осуществляется индивидуальная адресная помощь), так и организации социальной направленности (государственные и муниципальные учреждения, общественные организации). Часто помощь осуществляется по принципу pro bono, что подтверждает распространенность такой формы социальной ответственности [Granfield 2007; Pro bono... web; Rosenthal (ed.) 2015; Sadowsky, Pfeifer, Goodacre 2008; Scheuren 2007]. Она эффективна, так как позволяет организации использовать собственные ресурсы в виде профессиональных знаний и навыков сотрудников, материальных активов, гарантировать качество оказываемых на безвозмездной основе услуг, а также минимизировать затраты на реализацию социальных проектов.

Важным критерием для выбора адресатов социальной ответственности является место проживания ее субъектов: поддерживают свой город, район; заботятся о благополучии местного сообщества на территории присутствия компании. Например, компании участвуют в финансировании организации и проведения праздников, общественных мероприятий; помогают детям, инвалидам, малоимущим, пенсионерам, ветеранам; своим сотрудникам и клиентам; церковным организациям и местному сообществу. Весьма распро- 
страненным видом деятельности является защита окружающей среды, решение экологических проблем.

Такие социально ответственные практики обусловлены мотивами, имеющими морально-этические основания: гражданский долг; гордость; забота о городе, его жителях и его развитии; благодарность и т. п. Осознавая свою связь с территориальными общинами, сотрудники и руководители компаний при принятии решений, касающихся корпоративной социальной ответственности, учитывают интересы не только своей организации, но и местного населения. Выявленное нами влияние территориального фактора на корпоративную социальную ответственность обнаружено и в результате других исследований: фирмы, расположенные в небольших сообществах, могут лучше защитить свои заинтересованные стороны, чем географически рассредоточенные компании [Shi et al. 2017].

Малый и средний бизнес г. Волгограда не имеет возможности спонсировать проекты такого уровня, чтобы внести системные изменения в различные сферы российского общества, но готов участвовать в решении социально значимых задач региона. Субъекты корпоративной социальной ответственности хотели бы, чтобы их форматы помощи тиражировались, задавали тренды, то есть стали бы эффективными моделями позитивного изменения социальной среды.

Руководители компаний планируют в дальнейшем работать над проектами, связанными с детьми, молодежью, их обучением; помощью малоимущим жителям города; людям, которые находятся на лечении. Крупный бизнес готов стать донором конкретного фонда. Однако в качестве актуальных или потенциальных адресатов помощи опрашиваемые не указывают группы, которые нередко остаются за пределами внимания субъектов социальной ответственности, в том числе наркозависимых, лиц без определенного места жительства, находящихся в местах заключения.

Хотя бизнес помогает тем, кто нуждается в его поддержке (организации понимают нужды местного сообщества, знают о наиболее важных для региона проблемах и готовы принимать участие в их решении), он часто не информирует общественность о своих проектах в области корпоративной социальной ответственности. Одной из причин такой «скрытности» являются ограниченные финансовые возможности. Несмотря на то что корпоративная социальная ответственность обусловлена целями и мотивами, которые выходят за рамки экономической целесообразности, перспективы социально ответственной деятельности зависят, по мнению респондентов, от наличия свободных финансовых средств, которые уже можно не расходовать на личные нужды, оплату труда сотрудников, развитие бизнеса: «Скажем так, если бы мне нечего было есть, я бы не пошла в социальное предпринимательство. > ..> Когда нужно зарабатывать, спасать людей своих, сохранять и платить им зарплату, в меньшей степени думаешь, что надо там каким-то зебрам помочь или еще кому-то» (респондент № 7), «Если мы можем это себе финансово позволить, мы это делаем всегда. Мы никогда не отказываем. Проблема в том, как бы накопить жирка, чтоб можно было бы проявлять эту социальную ответственность в той мере, в которой ты хочешь» (респондент № 11). Инициаторами помощи нередко оказываются адресаты корпоративной социальной ответственности, которые сами общаются за помощью и с которыми бизнес в дальнейшем продолжает сотрудничество.

Исследование показало, что нравственные императивы и моральные обязательства, побуждающие субъектов заниматься социально ответственной деятельностью, не противоречат их личным интересам. Если есть финансовая возможность, они добровольно и безвозмездно помогают обществу. В условиях, когда в г. Волгограде корпоративная социальная ответственность, с одной стороны, обрела форму устойчивой социальной практики, а с другой - ее реализация имеет случайный, несистемный, эмоционально обусловленный характер, социальная ответственность конкретного индивида позволяет усилить эффект, который ответственность корпоративная оказывает на общество. 


\section{ПРИМЕЧАНИЕ}

${ }^{1}$ Работа выполнена при финансовой поддержке РФФИ и Администрации Волгоградской области, проект № 18-411-340013 «Морально-этические основания социальной ответственности в современном российском обществе (на примере организаций г. Волгограда)».

The study was conducted with the financial support of RFBR, project no. 18-411-340013 and Administration of the Volgograd region "Moral and ethic grounds of social responsibility in modern Russian society (illustrated by an example of organizations of Volgograd)".

\section{СПИСОК ЛИТЕРАТУРЫ}

Велехов web - Велехов Л. «Обычная жизнь страшнее, чем война». Филантроп Митя Алешковский в программе Леонида Велехова [Свобода] // https://www.svoboda.org/a/29628596.html.

Ильченко web - Ильченко E. «Атлет во благо»: как совместить личную выгоду и благотворительность [Форбс] // https://www.forbes.ru/ forbeslife/358981-atlet-vo-blago-kak-sovmestitlichnuyu-vygodu-i-blagotvoritelnost.

Маак, Плесс 2008 - Маак Т., Плесс Н. Ответственное лидерство. М.: Альпина Бизнес Букс, 2008.

Моя первая поездка... web - Моя первая поездка в дом престарелых, или как я провела День Победы [Старость в радость] // https:// starikam.org/news/moya-pervaya-poezdka-vdom-prestarelyx-ili-kak-ya-provela-den-pobedy.

Что движет благотворителями... web - Что движет благотворителями на самом деле? // https:// www.youtube.com/watch? $v=t Z h k L u p f$ Rl4\&feature $=$ youtu.be\&fbclid $=$ IwAR0NQ2fAR5 wva4I_DOjDCpP0XnIH-KLieVaoSoefuyU1Zg8 hxfljo-VKvQ.

Granfield 2007 - Granfield R. The Meaning of Pro Bono: Institutional Variations in Professional Obligations among Lawyers // Law \& Society Review. 2007. Vol. 41, iss. 1. P.113-146.

Pro bono... web - Pro bono: российские практики и вектор развития. Аналитический отчет по результатам исследовательского проекта // https://probono2017.ru/files Буклет_Pro_Bono_pyc_интерактивная.pdf. Rosenthal (ed.) $201 \overline{5}$ - Rosenthal R. J. (ed.). Volunteer ENGAGEMENT 2.0: Ideas and insights changing the world. Hoboken: John Wiley \& Sons, 2015.

Sadowsky, Pfeifer, Goodacre 2008 - Sadowsky S.J., Pfeifer D.L., Goodacre Ch. J. Survey of Pro Bono Services Provided by Practicing Prosthodontists
// Journal of Prosthodontics. 2008. Vol. 19, iss. 7. P. 553-556.

Scheuren 2007 - Scheuren F. The Pro Bono Statistician // Journal of the American Statistical Association. 2007. Vol. 102, № 477. P. 1-6.

Shi et al. 2017 - Shi G., Sun J., Zhang L., Jin Y. Corporate social responsibility and geographic dispersion // Journal of Accounting and Public Policy. 2017. Vol. 36, iss. 6. P. 417-428.

\section{REFERENCES}

Velekhov L. "Ordinary life is worse than war". Philanthropist Mitya Aleshkovsky in the program of Leonid Velekhov. URL: https:// www.svoboda.org/a/29628596.html.

IlchenkoE. "Athletefor Good": how to combine personal gain and charity. URL: https://www.forbes.ru/ forbeslife/358981-atlet-vo-blago-kak-sovmestitlichnuyu-vygodu-i-blagotvoritelnost.

Maak T., Pless N.M., 2008. Responsible leadership. Moscow, Alpina Business Books.

My first trip to a nursing home, or how I spent Victory Day. URL: https://starikam.org/news/moyapervaya-poezdka-v-dom-prestarelyx-ili-kak-yaprovela-den-pobedy.

What really drives philanthropists? URL: https:// www.youtube.com/watch?v=tZhkLupfR14\& feature=youtu.be\&fbclid=IwAR0NQ2fAR5wva4I DOjDCpP0XnIH-KLieVaoSoefuyU1Zg8_hxflj0VKvQ.

Granfield R., 2007. The Meaning of Pro Bono: Institutional Variations in Professional Obligations among Lawyers. Law \& Society Review?, vol. 41, iss. 1, pp. 113-146.

Pro bono: Russian Practices and Development Vector. Analytical Report on the Results of a Research Project. URL: https://probono2017.ru/files/ Буклет_Pro_Bono_pyc_интерактивная.pdf.

Rosenthal R. J. (ed.), 2015. Volunteer ENGAGEMENT 2.0: Ideas and insights changing the world. Hoboken, John Wiley \& Sons.

Sadowsky S.J., Pfeifer D.L., Goodacre Ch.J., 2008. Survey of Pro Bono Services Provided by Practicing Prosthodontists. Journal of Prosthodontics, vol. 19, iss. 7, pp. 553-556.

Scheuren F., 2007. The Pro Bono Statistician. Journal of the American Statistical Association, vol. 102, no. 477, pp. 1-6.

Shi G., Sun J., Zhang L., Jin Y., 2017. Corporate social responsibility and geographic dispersion. Journal of Accounting and Public Policy, vol. 36 , iss. 6 , pp. 417-428. 
T.C. Горина. Субъекты и адресаты социальной ответственности (на примере организаций г. Волгограда)

\section{Information about the Author}

Tatyana S. Gorina, Candidate of Sciences (Philosophy), Associate Professor, Department of Philosophy, Volgograd State University, Prosp. Universitetsky, 100, 400062 Volgograd, Russian Federation, tsgorina@gmail.com, socphil@volsu.ru,https://orcid.org/0000-0001-5114-1821

\section{Информация об авторе}

Татьяна Сергеевна Горина, кандидат философских наук, доцент кафедры философии, Волгоградский государственный университет, просп. Университетский, 100, 400062 г. Волгоград, Российская Федерация, tsgorina@gmail.com, socphil@volsu.ru, https://orcid.org/0000-0001-5114-1821 